\title{
Effect of Outlet Plenum Volume During Flow Boiling Inside Plain Parallel Microchannel
}

\author{
Gaurav Hedau', Rishi Raj ${ }^{2}$, Sandip K. Saha ${ }^{1}$ \\ ${ }^{1}$ Indian Institute of Technology Bombay \\ Powai, Mumbai, India \\ gauravhedau89@gmail.com; sandip.saha@iitb.ac.in \\ ${ }^{2}$ Indian Institute of Technology Patna \\ Bihta, Patna, India \\ rraj@iitp.ac.in
}

\begin{abstract}
In this paper, the effect of outlet plenum volume in reducing instability and enhanced thermal performance during flow boiling inside fourteen parallel copper plain microchannel is reported. Two different sets of outlet plenum design are studied having the outlet plenum volume same as the inlet plenum volume (V1) and the outlet plenum volume with eight times of the volume of inlet plenum (V8). The plain microchannel with the $\mathrm{V} 8$ microchannel shows $4.5^{\circ} \mathrm{C}$ less surface temperature compared to that with the $\mathrm{V} 1$ microchannel for the mass flux of $250 \mathrm{~kg} / \mathrm{m}^{2} \mathrm{~s}$ and heat flux of $220 \mathrm{~W} / \mathrm{cm}^{2}$. The larger outlet plenum volume efficiently removes vapour generated inside the microchannel, thereby reducing the fluctuations in temperature, pressure drop and mass flux during flow boiling.
\end{abstract}

Keywords: Microchannel, Outlet plenum volume, Flow Boiling, Instability.

\section{Introduction}

The microchannel heat exchanger is primarily used to dissipate very high heat flux through boiling of cooling fluid flowing inside it. During heat transfer at high heat fluxes, due to high vapour generation, instabilities occur inside the channel [1]. Major instabilities occur due to backflow of vapour in the upstream direction which temporarily blocks fresh incoming fluid, causing oscillations in temperature, pressure, mass flux and a prime reason for attending the premature critical heat flux (CHF) [2]. Researchers used many techniques to reduce the flow boiling instabilities and enhance the heat transfer performance of microchannel heat exchanger. Kandlikar et al. [3] studied the effect of inlet pressure restrictor (pressure drop element of $4 \%$ and $51 \%$ throttling before each channel) combined with artificial nucleation site (laser-drilled holes of diameter 5 to $30 \mu \mathrm{m})$ to stabilize the flow boiling instabilities in a parallel microchannel with dimensions of $1054 \times 197 \mu \mathrm{m}$ and hydraulic diameter of $332 \mu \mathrm{m}$. They observed a decrease in the instability using only pressure drop element and an increase in the instability using only artificial nucleation site. Complete suppression of instability was observed with $4 \%$ throttling along with artificial nucleation site, which enhances heat transfer and reduces surface temperature. Kosar [4] experimentally investigated the effect of length of inlet restrictor having dimension of $20 \mu \mathrm{m}$ width and $264 \mu \mathrm{m}$ depth at inlet of each microchannel ( $200 \mu \mathrm{m}$ wide, $264 \mu \mathrm{m}$ deep and $1 \mathrm{~cm}$ length) in reducing instability during flow boiling. Inlet restrictor with length of $400 \mu \mathrm{m}$ showed maximum CHF value. In another study, Wang et al. [5] compared the flow boiling performance of three different inlet-outlet modifications in microchannel of hydraulic diameter of $186 \mu \mathrm{m}$. The microchannel with inlet restrictor showed less instability and performed well at the higher heat flux. The reduction in flow boiling instability using diverging microchannel was studied by Agrawal et al. [6]. Three different divergence angles of $4^{\circ}, 8^{\circ}$ and $12^{\circ}$ were studied which showed that the pressure drop and instability reduce during flow boiling in microchannel with divergence angle of $12^{\circ}$. In the published literature, the effect of outlet plenum volume design on instabilities and thermal performance of microchannel heat exchanger is not studied yet. Hence, in this study, the effect of outlet plenum volume on the reduction of instabilities and enhancement in flow boiling thermal performance is evaluated at a mass flux of 250 with heat flux varies from 23 to $220 \mathrm{~W} / \mathrm{cm}^{2}$. 


\section{Experimental Setup and Procedure}

\section{1. Test Section Design and Fabrication}

Fourteen plain parallel microchannel with the dimension of each channel of $315 \mu \mathrm{m}$ (width) $\times 600 \mu \mathrm{m}$ (depth) $\times 10 \mathrm{~mm}$ (length) is fabricated using CNC micro-milling machine on copper surface. These channels are fabricated on a $10 \times 10 \mathrm{~mm}$ footprint area on the top surface of a copper block neck portion, as shown in figure 1. A cartridge heater having diameter of $6.35 \mathrm{~mm}$ and length $26 \mathrm{~mm}$ is inserted at the bottom of the copper block. The copper block is inserted inside a Teflon block on which inlet and outlet plenum are machined as illustrated in exploded view of test section in figure 1 . The plenum is fabricated in the dumbbell shape having the same depth as the microchannel depth which ensures an equal single-phase flow distribution in the channels [9]. A transparent polycarbonate cover (12 $\mathrm{mm}$ thick) is fixed on the top of the Teflon copper block. The setup is then tighten using nut and bolts to seal the test section with the use of silicon-based sealant. Inlet and outlet ports having vertically top entry and exit for the fluid are fabricated inside the polycarbonate cover. Two types of outlet plenum design have been used in this study. First design consists of outlet plenum volume same as inlet plenum volume (machined on Teflon block) denoted as V1 and second design consists of outlet plenum having volume eight times of inlet plenum volume denoted as V8 (machined on polycarbonate cover). For measuring surface temperature, three T-type thermocouples (T1, T2, T3) are used. Each thermocouple is inserted in a hole of $1 \mathrm{~mm}$ diameter, $5 \mathrm{~mm}$ deep drilled and 2 $\mathrm{mm}$ below the top surface of microchannel along the length as shown in figure 1. For measuring heat flux at the bottom of microchannel, two thermocouples (T4 and T5) are placed $3 \mathrm{~mm}$ apart along vertical direction below thermocouple T2. For measuring pressure drop across the microchannel, two holes are drilled $2 \mathrm{~mm}$ before and $2 \mathrm{~mm}$ after microchannels.

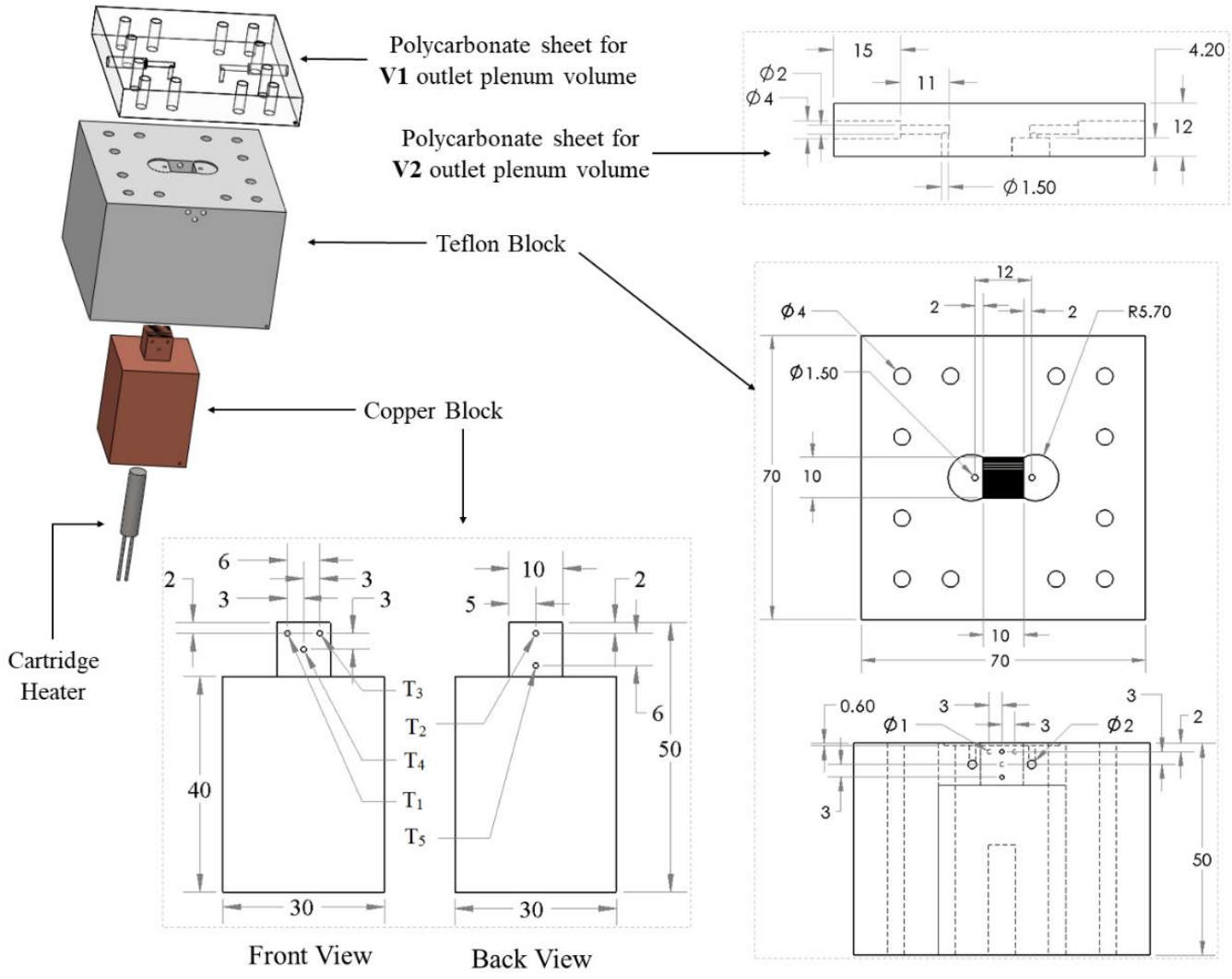

Fig. 1: Test section with dimensions (in $\mathrm{mm}$ ).

\section{2. Experimental Flow Loop}

For evaluating the performance of microchannel, a closed flow loop is fabricated using deionised (DI) water as the cooling fluid as shown schematically in figure 2. Flow loop includes a degassing unit (reservoir for DI water), a peristaltic 
pump (Cole-Parmer make), a dampener (Masterflex made), a mass flow meter (Micro Motion ELITE Coriolis Flow and density meter-CMF010M), a preheater, microchannel test section and a condenser. The readings from thermocouples (T(T-type), absolute pressure transducer (Omega make -PX305-050AI), differential pressure transducer ( Omega make PXM459-350HDWUI) and mass flow meter are acquired by a data acquisition system (NI crio- 9066 with NI 9023,9212 9212 and 9472 cards) at the rate of 10 data per second, which is connected with a computer. The water in degassing unit is is kept at $100{ }^{\circ} \mathrm{C}$ for degassing purpose with the help of heater. The peristaltic pump draws water from degassing unit to dampener where the fluctuations in flow rate due to pump damps out. The preheater maintains a constant inlet subcooling temperature to test section. A DC power source supplies power to the cartridge heater. A high-speed camera (Phantom Miro 110 ) is used to capture and analyse the video of flow boiling inside microchannel.

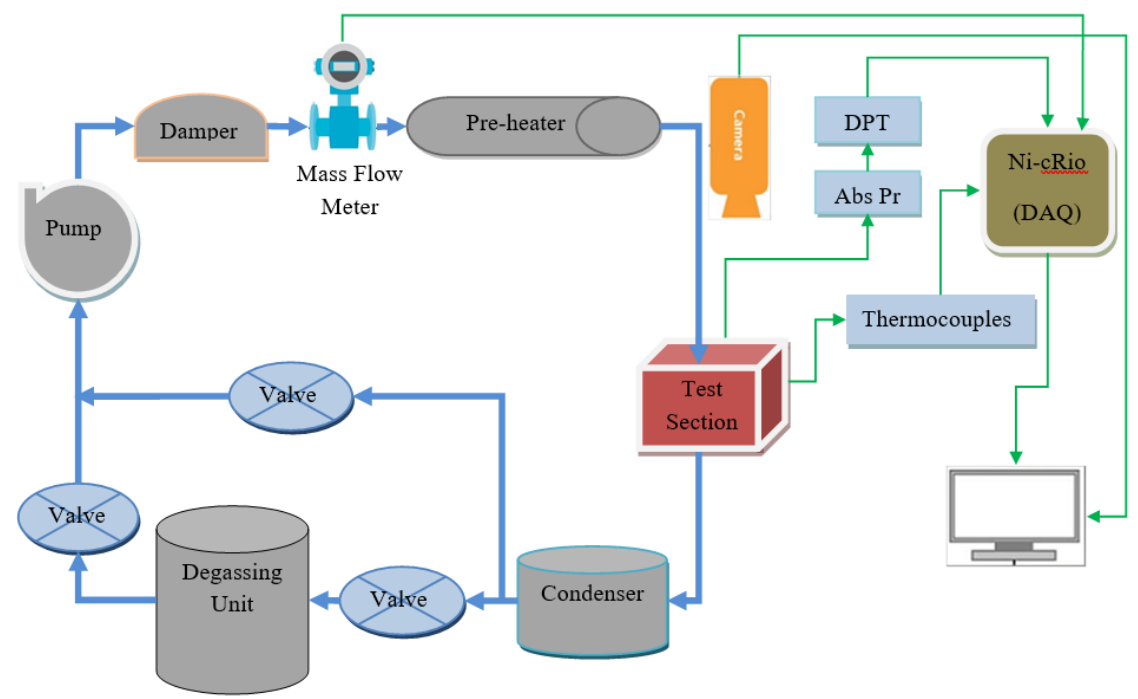

Fig. 2: Flow loop for evaluating the performance of microchannel.

\section{4. Data Reduction and Uncertainty}

In this study the heat input $\left(Q_{c}\right)$ given by cartridge heater is varied from 30 to $240 \mathrm{~W}$. Correspondingly the actual heat flux $(q ")$ conducted at the bottom surface of microchannel (footprint area $(A)=1 \mathrm{~cm}^{2}$ ) is calculated using thermocouples $\left(\mathrm{T}_{2}\right.$, $\left.\mathrm{T}_{4}, \mathrm{~T}_{5}\right)$ in vertical direction. Heat flux $\left(q^{\prime \prime}\right)$, which is dissipated by microchannel, is calculated using one-dimensional Fourier law of heat conduction and is given as,

$$
q^{\prime \prime}=-k_{c} \frac{d T}{d y}
$$

where, $k_{c}$ is thermal conductivity of copper, $d T$ is the difference between two thermocouples reading, and $d y$ is the distance between thermocouple. The difference between total heat input and heat conducted at the bottom of microchannel is dissipated in atmosphere which is given by $Q_{L}$ (heat loss) as below.

$$
Q_{L}=Q_{c}-q^{\prime \prime} A
$$

The total heat loss is found to be around 8 to $23 \%$ as heat input varies from 30 to $240 \mathrm{~W}$. The uncertainty in calculating heat flux is $\pm 2 \%$. The uncertainty in measurement by the thermocouple, differential pressure transducer and mass flow meter are $\pm 0.2{ }^{\circ} \mathrm{C}, \pm 0.875 \mathrm{mbar}, \pm 25 \mathrm{~kg} / \mathrm{m}^{2} \mathrm{~s}$, respectively. 


\section{Results and Discussion}

In the present study, two types of microchannel design are tested PV1, PV8, corresponds to plain surface microchannel with outlet plenum volume of V1, and V8, respectively. The outlet plenum volume of V8 is the eight times of the outlet plenum volume of V1. De-ionised (DI) water is used as the cooling fluid in the experiments with a mass flux of $250 \mathrm{~kg} / \mathrm{m}^{2} \mathrm{~s}$. The heat input to the cartridge heater is varied from 30 to $240 \mathrm{~W}$. The inlet subcooling is maintained at $20 \pm 1{ }^{\circ} \mathrm{C}$. The error bar in figures shows the standard deviation $(+\sigma$ and $-\sigma)$ of the parameter measured, which depicts fluctuations in data.

\section{1. Flow regime at different heat flux and mass flux}

For a given mass flux, as heat flux increases, different flow regimes appear inside the microchannel. Single-phase flow regime appears for both types of microchannel at the heat flux of $23 \mathrm{~W} / \mathrm{cm}^{2}$. As the surface temperature increases above the saturation temperature, the nucleation of bubble starts on the surface of the microchannel. Due to the small dimensions of microchannel the bubble remains confined between the channel walls during the growth and detachment from wall surface. Moreover, bubbles detached and combine to form slug flow along the flow inside microchannel. Bubble-slug flow regime appears in microchannel at heat flux of $42 \mathrm{~W} / \mathrm{cm}^{2}$ for mass flux of $250 \mathrm{~kg} / \mathrm{m}^{2} \mathrm{~s}$.

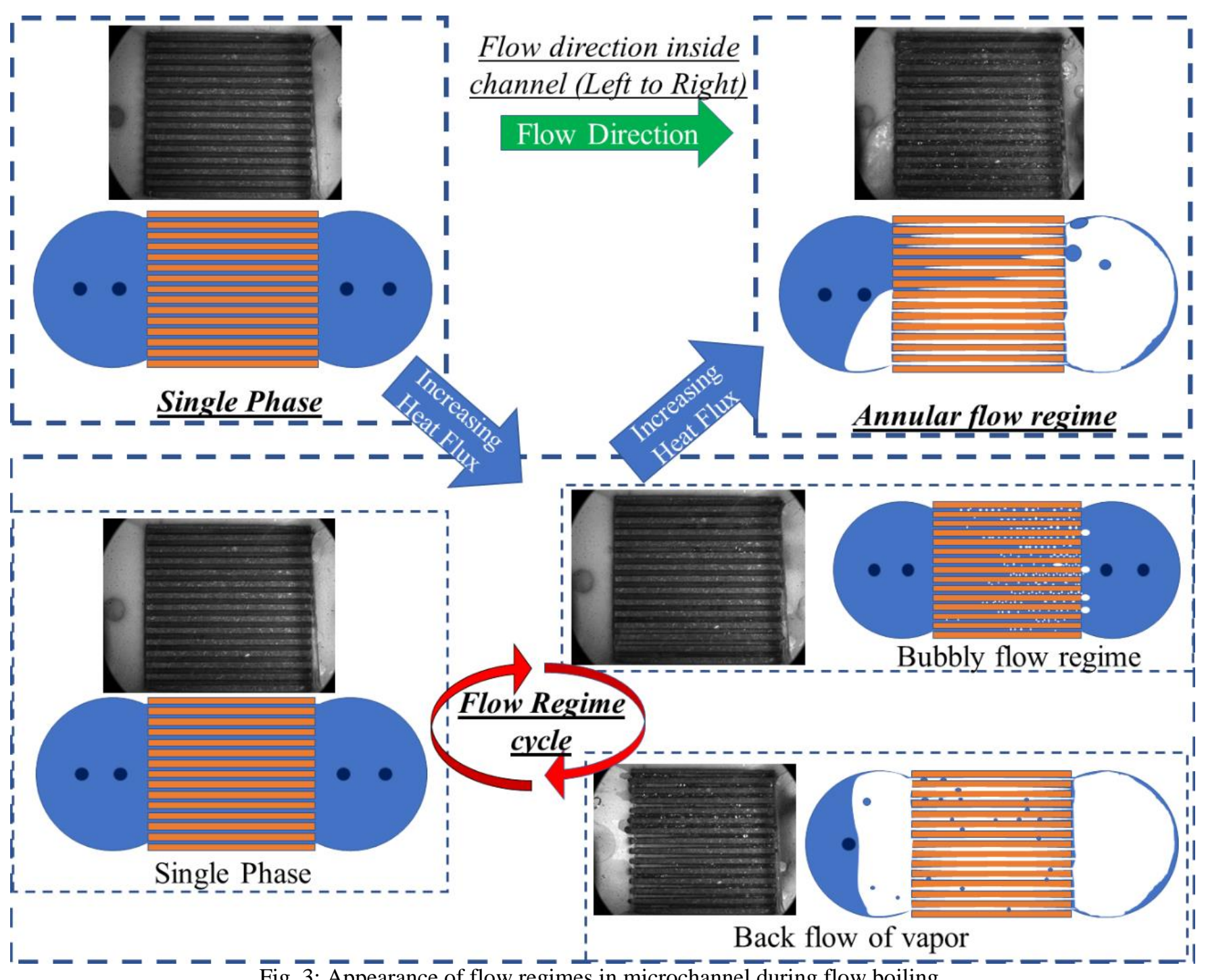


At medium heat flux ( 62 to $\left.137 \mathrm{~W} / \mathrm{cm}^{2}\right)$, large cyclic fluctuations in temperature, pressure and mass flux appear. This is due to cyclic fluctuations in flow regime from single-phase liquid, slug to annular with partial dry out. This cyclic fluctuation can be termed as flow regime cycle, which occurs primarily due to simultaneous backflow of vapour from all parallel channels in the upstream direction as shown in figure 3. When vapour bubble blocks the microchannel inlet, the temperature and pressure drop increase, whereas mass flux decreases. As pump continuously supply the water, the pump pressure overcomes the backflow pressure of vapour, and all the channels are flooded with single-phase liquid, due to which the surface temperature and pressure drop decrease; however, mass flux increases. At the higher heat flux (165 to 220 $\mathrm{W} / \mathrm{cm}^{2}$ ), annular flow regime with partial dry out appears inside the channels.

\section{2. Boiling curve}

The variation of surface superheat (surface temperature $\left(T_{s}\right)$ - saturation temperature $\left(T_{\text {sat }}\right)$ ) with increasing heat flux for mass flux of $250 \mathrm{~kg} / \mathrm{m}^{2} \mathrm{~s}$ is shown in figure 4 . It can be observed that at the lower heat flux $\left(<42 \mathrm{~W} / \mathrm{cm}^{2}\right)$, the surface temperatures for all microchannels are nearly equal due to the presence of single-phase liquid inside channel, which dissipates heat with convective heat transfer. This shows that the larger volume of outlet plenum in microchannel is not effective in reducing the surface temperature in the single-phase heat transfer. However, as heat flux increases, a significant difference in the surface temperatures between different designs is observed. For mass flux of $250 \mathrm{~kg} / \mathrm{m}^{2} \mathrm{~s}$, the PV8 microchannel shows $4.5^{\circ} \mathrm{C}$ less surface temperature compared to that of PV1 at a higher heat flux of $220 \mathrm{~W} / \mathrm{cm}^{2}$. The large volume of outlet plenum provides extra space to accommodate vapour into the outlet plenum before the vapour exits through the outlet port. This results in a better movement of vapour in the downstream direction and an increase in rewetting inside the microchannel leading to the reduction in the surface temperature.

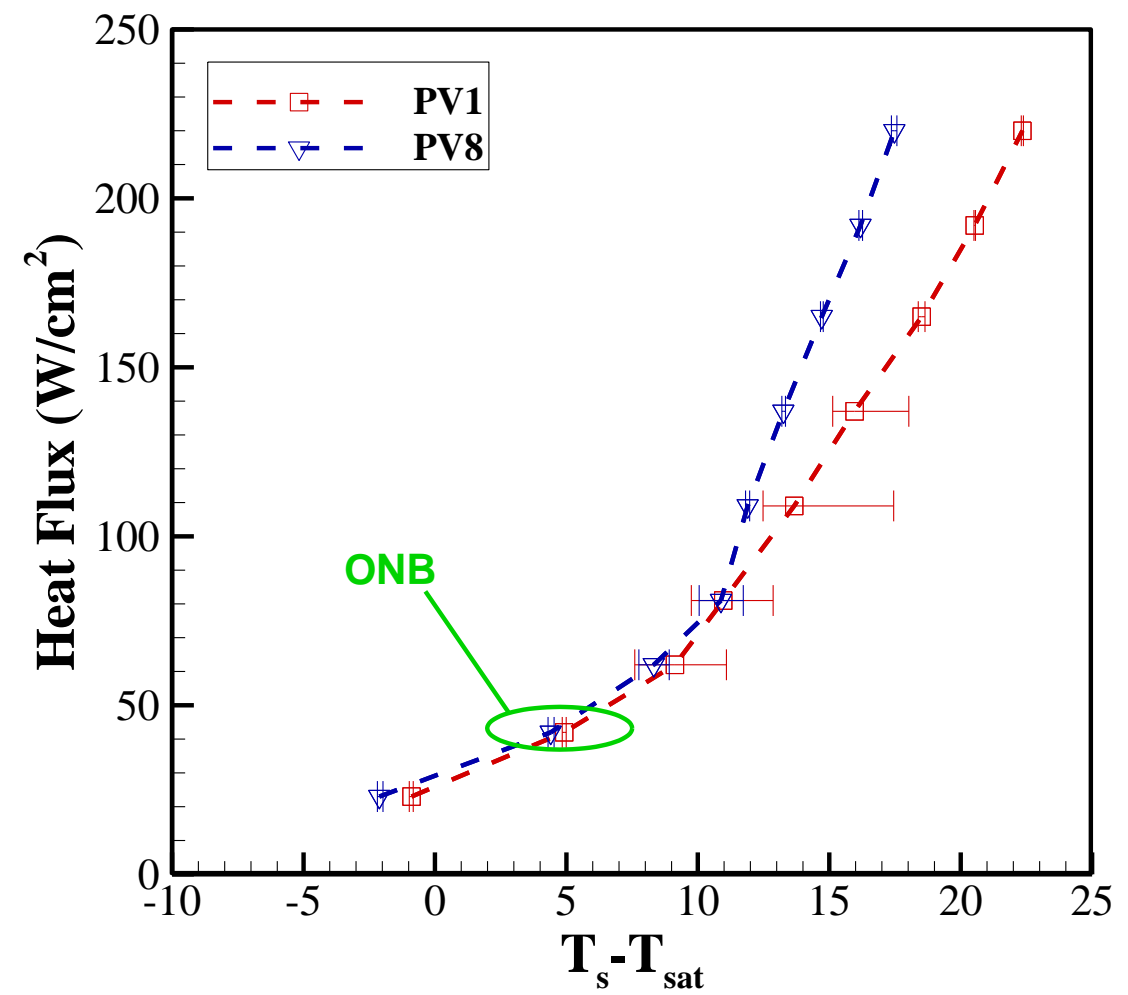

Fig. 4: Boiling curve for PV1 and PV8 microchannels at the mass flux of $250 \mathrm{~kg} / \mathrm{m}^{2} \mathrm{~s}$. 


\section{3. Pressure drop variation with heat flux}

The comparison of pressure drop across the microchannel between different designs of microchannel (PV1 and PV8) at the mass flux of $250 \mathrm{~kg} / \mathrm{m}^{2} \mathrm{~s}$ is shown in figure 5. At low heat flux $\left(<42 \mathrm{~W} / \mathrm{cm}^{2}\right)$, due to the presence of single-phase flow inside the channel, the pressure drop value is nearly equal for all types of microchannel. As the heat flux increases above the onset of nucleate boiling (ONB) point, the pressure drop starts to increase due to bubble generation as bubble hinders the flow of the incoming fluid, increasing the pressure drop with fluctuations. At moderate to high heat flux, in case of PV1, the difference in pressure drop increases, which is higher compared to that in PV8 at the mass flux of $250 \mathrm{~kg} / \mathrm{m}^{2} \mathrm{~s}$. Hence, a larger outlet plenum decreases the pressure drop, when the rate of vapour generation is high at the heat flux of $220 \mathrm{~W} / \mathrm{cm}^{2}$, where PV8 shows 4.2 mbar lower pressure drop compared to PV1.

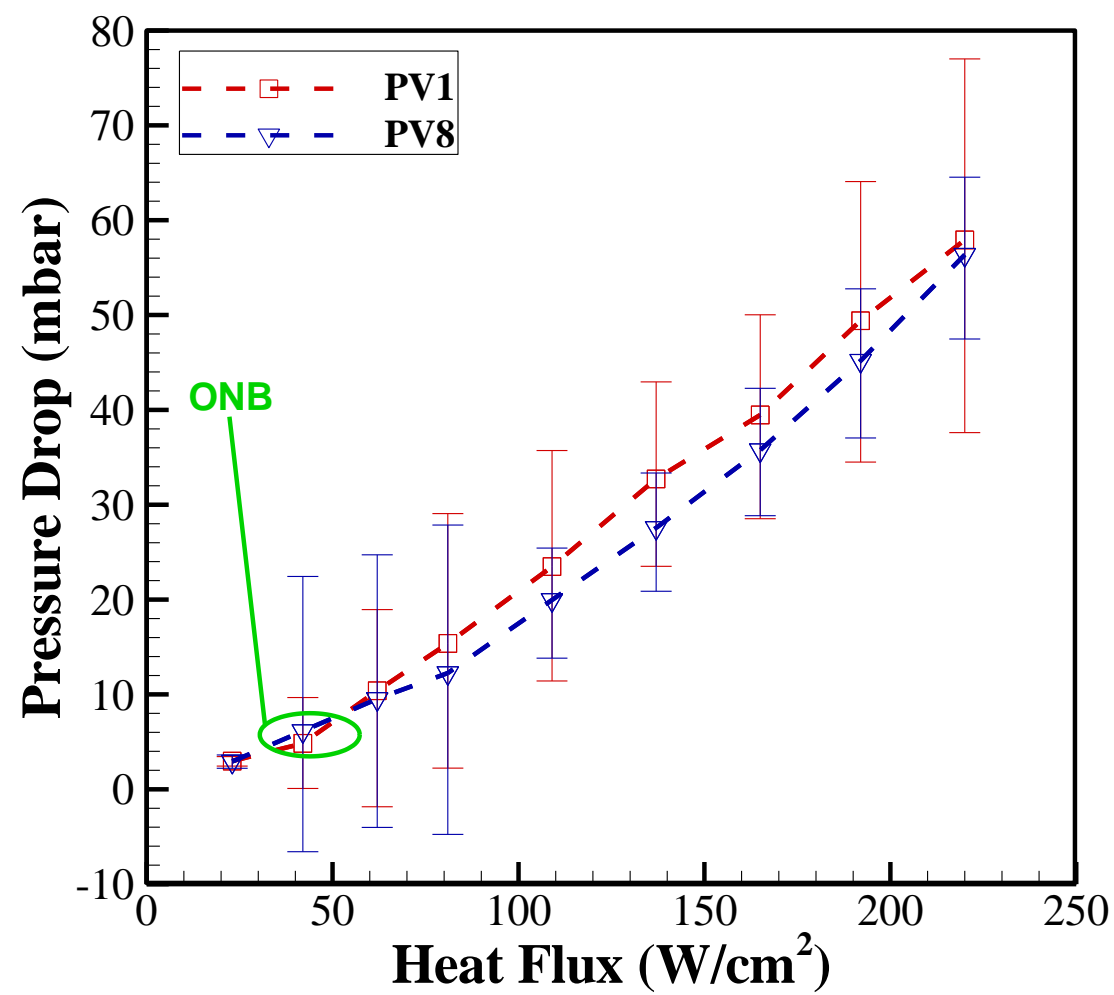

Fig. 5: Pressure Drop variation with heat flux for PV1 and PV8 microchannels at the mass flux of $250 \mathrm{~kg} / \mathrm{m}^{2} \mathrm{~s}$.

\section{4. Fluctuations in Mass Flux}

The fluctuations in mass flux for $250 \mathrm{~kg} / \mathrm{m}^{2} \mathrm{~s}$ with varying heat flux is shown in figure 6 . The mass flux fluctuates maximum at moderate heat flux where the flow regime cycle appears. The fluctuations at moderate heat flux are maximum for PV1 microchannel for both the cases of mass flux. For the mass of $250 \mathrm{~kg} / \mathrm{m}^{2} \mathrm{~s}$, due to the inefficient removal of generated vapour from the PV1 microchannel, the fluctuations are high for wide range of heat flux (62 to $137 \mathrm{~W} / \mathrm{cm}^{2}$ ) as compared to PV8. At heat flux of $62 \mathrm{~W} / \mathrm{cm}^{2}$, the fluctuations in mass flux in PV1 is $\left(+\sigma=116.45,-\sigma=125.35 \mathrm{~kg} / \mathrm{m}^{2} \mathrm{~s}\right)$ while these fluctuations in PV8 are found to be $\left(+\sigma=61.19,-\sigma=59.16 \mathrm{~kg} / \mathrm{m}^{2} \mathrm{~s}\right)$. The PV8 microchannel having large outlet plenum volume results in lower fluctuations, as it provides lesser resistance to the bubble moving in the downstream direction towards the outlet plenum where it can freely expand. 


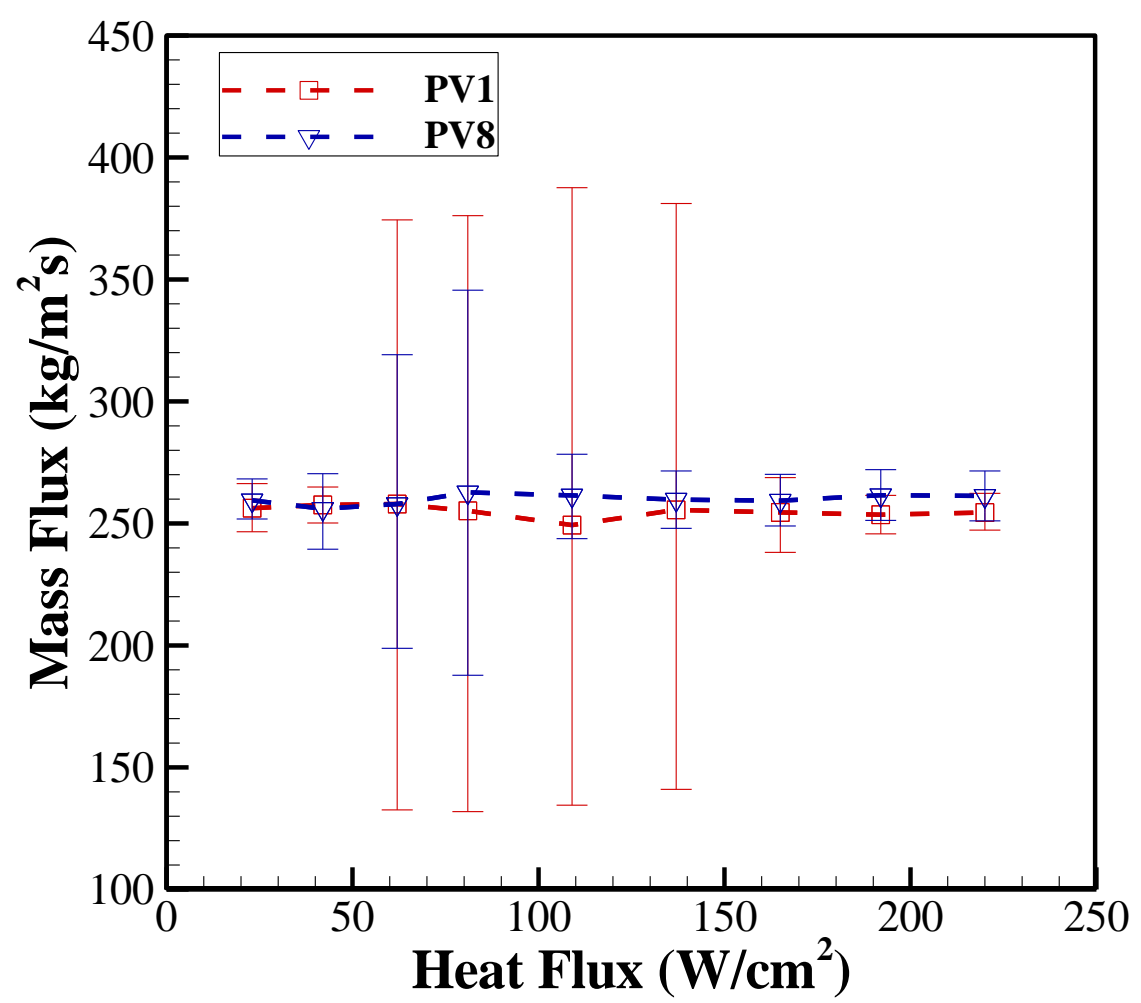

Fig. 6: Mass flux fluctuations with heat flux for the PV1 and PV8 microchannels.

\section{Conclusion}

In this paper, an experimental study on the effect of volume of the outlet plenum in fourteen plain parallel copper microchannel at a mass flux of $250 \mathrm{~kg} / \mathrm{m}^{2} \mathrm{~s}$ is performed. By increasing outlet plenum volume by eight times of the inlet plenum volume, the significant reduction in surface temperature at high heat flux $\left(220 \mathrm{~W} / \mathrm{cm}^{2}\right)$ by $4.5{ }^{\circ} \mathrm{C}$ is achieved for the mass flux of $250 \mathrm{~kg} / \mathrm{m}^{2} \mathrm{~s}$. The magnitude of fluctuations in surface temperature, pressure drop and mass flux is also observed to be less in case of larger outlet plenum volume microchannel. Therefore, the implementation of large outlet plenum volume as compared to the inlet plenum volume has the tendency to reduce fluctuation during flow boiling. Also, for the same heat flux, the surface temperature reduces which increases the CHF value of the microchannel heat exchanger.

\section{Acknowledgements}

Authors thank Science and Engineering Research Board (SERB), Department of Science and Technology, India (Project No. SB/S3/MMER/0023/2014) for funding this work.

\section{References}

[1] Y. K. Prajapati and P. Bhandari, "Flow boiling instabilities in microchannels and their promising solutions-A review," Experimental Thermal and Fluid Science, vol. 88, pp. 576-593, 2017.

[2] A. E. Bergles and S. G. Kandlikar, "On the nature of critical heat flux in microchannels," ASME Journal of Heat Transfer, vol. 127, no. 1, pp. 101-107, 2005.

[3] S. G. Kandlikar, W. K. Kuan, D. A. Willistein and J. Borrelli, "Stabilization of flow boiling in microchannels using pressure drop elements and fabricated nucleation sites," ASME Journal of Heat Transfer, vol. 128, no. 4, pp. 389-396, 2006.

[4] A. Koşar, C. J. Kuo and Y. Peles, "Suppression of boiling flow oscillations in parallel microchannels by inlet restrictor," Journal of Heat Transfer, vol. 128, no. 3, pp. 251-260, 2006. 
[5] G. Wang, P. Cheng and A. E. Bergles, "Effects of inlet/outlet configurations on flow boiling instability in parallel microchannels," International Journal of Heat and Mass Transfer, vol. 51, no. 9-10, pp. 2267-2281, 2008.

[6] A. Agrawal, V. Duryodhan and S. Singh, "Pressure drop measurements with boiling in diverging microchannel," Frontiers in Heat and Mass Transfer (FHMT), vol. 3, no. 1, 2012.

[7] F. Yang, X. Dai, Y. Peles, P. Cheng, J. Khan and C. Li, "Flow boiling phenomena in a single annular flow regime in microchannels (I): Characterization of flow boiling heat transfer," International Journal of Heat and Mass Transfer, vol. 68, pp. 703-715, 2014.

[8] D. Sharma, D. Ghosh, S. K. Saha and R. Raj, "Thermohydraulic characterization of flow boiling in a nanostructured microchannel heat sink with vapor venting manifold," International Journal of Heat and Mass Transfer, vol. 130, pp. 1249-1259, 2019.

[9] A. Siddique, B. J. Medhi, A. Agrawal, A. Singh and S. K. Saha, "Design of a collector shape for uniform flow distribution in microchannels," Journal of Micromechanics and Microengineering, vol. 27, no. 7, pp. 075026, 2017. 